\title{
Correction to: Modeling alcohol-induced neurotoxicity using human induced pluripotent stem cell-derived three-dimensional cerebral organoids
}

Thiago Arzua, Yasheng Yan, Congshan Jiang, Sarah Logan, Reilly L. Allison, Clive Wells, Suresh N. Kumar,

Richard Schäfer and Xiaowen Bai

Correction to: Translational Psychiatry https://doi.org/10.1038/s41398-020-01029-4 published online 13 October 2020

The original version of this article unfortunately contained several typos in the unit of ethanol concentration.
The unit of ethanol concentration should be "mg/dL" but not " $\mathrm{mg} / \mathrm{mL}$ ". The original article has been corrected.

Published online: 01 February 2021 